Mr. O. F. Hudson. This work had been undertaken at the request of the Publication Committee of the institute, and in preparing it Mr. Hudson received and incorporated methods adopted by well-known workers both in America and this country. The paper deals more especially with the final stage in the preparing of specimens for microscopic examination, but as the author points out, the effects of previous operations must always be borne in mind. There is now an increasing consensus of opinion among the most skilled metallographers that grinding on mechanically-driven discs produces too severe an alteration in the surface structure of a metal or alloy, which is likely to create difficulties in their microscopic interpretation after etching, and that hand grinding, although slower, is much more trustworthy. This is neither more nor less than a return to the technique of the late M. Osmond, whose skill in the preparation of a specimen for microscopic examination has never been surpassed. The discussion on Mr. Hudson's paper was in a high degree illuminating, and showed the institute members at their best. When the complete paper and discussion are published they will certainly be a standard work of reference.

Four other papers were submitted. Of these, that by $\mathrm{Mr}$. Whyte, on the microchemistry of corrosion, and that by Mr. Haughton, on the constitution of the alloys of copper with tin, were read and discussed. The remaining two were taken as read, and will be discussed by written communications.

H. C. H. Carpenter.

\section{SUPPLIES OF LABORATORY AND OPTICAL GLASS APPARATUS.}

Reports of the British Science Guild.

THE British Science Guild has just issued two reports dealing with matters of national moment at the present time. One is concerned with the provision of glass apparatus for educational purposes, and the other with optical glass and the position of technical optics generally in this country. The reports are here reprinted, and it will be seen that they are both informative and helpful. First, with regard to laboratory ware, it appears that, as the result of an inquiry instituted by committees of the guild, working in co-operation with the Association of Public School Science Masters, about three-quarters of the schools or other bodies requiring laboratory glassware have undertaken to use British glass during the war, and for a period of three years after, provided that the price is not prohibitive. As explained in a letter to NATURE of February I8 (p. 67o) the British Laboratory Ware Association has made arrangements for the supply of laboratory glassware and similar materials from British manufacturers. The British Science Guild has, by its action, presented the association and British glass manuíacturers generally with an assurance of support which should be of the greatest value to them.

The report of the Technical Optics Committee of the guild should cause serious attention to be given to the establishment of a British Institute of Technical Optics. In the last annual report of the guild it was pointed out that this necessity had been impressed upon the education department of the London County Council continuously during the past twelve years. Scientific experts, leading members of the optical industry, and educational experts have combined to urge the paramount importance of the definite proposals which have been formulated, but the scheme still hangs fire. Meanwhile our scientific and industrial rivals on the Continent, taking note of successful No. 2369 , VOL. 95] developments on a small scale which have been originated here, have gone forward to new developments with increased vigour and with highly successful results.

\section{(I) Provision of Glass Apparatus for Educational Purposes.}

In the past practically all the glass and procelain apparatus used in chemical laboratories in this country has been manufactured in Germany and Austria. As the supply is now cut off and the stocks held by British dealers are almost exhausted, the problem of obtaining apparatus for educational and technical purposes has become a serious one.

The Joint Committee is informed that efforts are now being made by several firms to introduce the manufacture of glass apparatus into this country, and being in hearty sympathy with these efforts, it has considered in what way the British Science Guild may best assist. In these efforts the committee has cooperated with the Association of Public School Science Masters, and has taken action along two main lines, viz. :-

(A) Endeavouring to obtain assurances of support for British makers of educational glass ware after the war as well as now.

(B) Obtaining information from educational institutions respecting the principal types and sizes of glass apparatus in greatest demand.

\section{(A) Assurances of Support for British Makers of Scientific Glass Ware.}

It is understood that the efforts during the last three months by certain British glass manufacturers have been attended with satisfactory results as regards the quality of the products. Economic and manufacturing conditions have prevented British glass apparatus being sold at so low a price as has been paid in the past for German material. As these conditions will probably remain unchanged, British manufacturers have been naturally disinclined to expend the necessary capital in establishing the proposed new industry here while there is every likelihood that they will be undersold in the British market by their competitors when the war is over. The Joint Committee is informed that this has acted as a strong deterrent to British glass manufacturers contemplating the production of scientific glass apparatus.

The Joint Committee therefore has endeavoured to ascertain how far it is probable that educational institutions would undertake to buy only British-made glass and porcelain apparatus during the war, and for a period of three years after.

Inquiries were made in this direction by the hon. secretary of the Association of Public School Science Masters, who is a member of the Joint Committee. from the headmasters of all schools represented on the Headmasters' Conference. Out of the hundred and ten (I Io) schools so represented, no fewer than seventyeight (78), i.e., 7 I per cent., have definitely promised to authorise their science staffs to purchase, as far as possible, only British-made glass apparatus during and for a period of three years after the conclusion of the war. As these promises have been received from almost all the largest schools, both boarding and day, it may be assumed that manufacturers as well as dealers will receive adequate support from the "conference schools."

The guild also issued about $75^{\circ}$ letters of inquiry

(a) Local education authorities.

(b) Governors of secondary schools.

(c) Governing bodies of technical institutions.

(d) Senates of universities and university colleges, and has received a very large number of replies. 
The proportion of definite repplies coming in at once has been smaller than in the case of the public schools from the fact that various committees have had to be consulted before definite promises could be given, but the replies which have been received have been quite satisfactory-of the definite replies received about 72 per cent. are sympathetic, and promises are given to purchase only British-made apparatus as requested, subject in many cases to the proviso that the increased cost is not prohibitive.

A considerable number of the replies, while generally sympathetic, give no guarantee, the reason being in most cases that the matter rests with a higher authority, such as a county council, or board of governors, from whom no definite reply had been obtained. Some authorities, also, while sympathetic, do not feel able to bind their successors, and one authority suggests that only the purchase of German and Austrian apparatus should be barred.

The endeavour to obtain the value of the apparatus used in such institutions has not resulted in any very precise information, but from the facts before the committee it is clear that the value of such apparatus must at least run to some thousands of pounds.

(B) Types and Sizes of Apparatus most in Demand.

Inquiries as to the principal types and sizes of apparatus most generally used have been made on behalf of the Joint Committee from public schools and technical schools. It was felt by the Joint Committee that this information would be of considerable value to glass-makers, as there is a very strong feeling among those concerned with the chemical apparatus trade that at the present time flasks, beakers, basins, etc., are supplied in an unnecessarily large variety of shapes and sizes.

Judging from the replies received from the institutions above referred to, the following represent the apparatus most in demand:-

Test Tubes. -6 in. $\times \frac{3}{4}$ in., 2 in. $\times \frac{1}{4}$ in., and, in smaller quantities, 6 in. $\times I$ in., 5 in. $\times \frac{5}{8}$ in., and 2 in. $\times \frac{1}{2}$ in.

BEAKERs.-Squat form, lipped, 200 c.c., 300 c.c., and, in smaller quantities, I50 c.c., 500 c.c., rooo c.c.

BEAKERs.-High form, in the same sizes as above, but in smaller quantities.

Flasks.-Flat bottom, Ioo c.c., 250 c.c., 500 c.c., and, in smaller quantities, 1000 c.c., 1500 c.c., 2000 c.c.

FLASKS.-Round bottom, 250 c.c., 500 c.c.

Tubulated Retorts. - I50 c.c.

Funnels. $-6.5 \mathrm{~cm}$.

Distilling Flasks.- 100 c.c., 250 c.c., 500 c.c.

Evaporating Dishes.-50 c.c., IOO c.c., 200 c.c., and, in smaller quartities, rooo c.c., and 2000 c.c.

CRUCIBLES.- I5 c.C. and 25 c.c.

In conclusion, the Joint Committee desires to express its strong conviction that every effort should be made to facilitate and encourage the manufacture of glass and porcelain apparatus in the United Kingdom. It therefore urges the advisability of asking the Board of Trade to watch the new industry, and, if necessity should arise, to use its endeavours to modify any restrictions at present existing which may be detrimental to the carrying on and extension of the industry.

(2) The Manufacture of Optical Instruments and Matters Relating Thereto.

\section{NECESSITY FOR ACTION.}

The British Science Guild, having inquired carefully, by means of a strong and representative expert committee, into the effect of the outbreak of hostilities on matters of national importance connected with the manufacture of optical instruments in the country generally, submits this report to the Government, and in doing so emphasises the pressing urgency of the subjects referred to.

\section{Supply of Glass. (a) The General Case.}

(I) In the first place the inquiry referred to was directed to the consequences of the sudden stoppage of the supply of German optical glass on which this country had increasingly relied for many recent years. A letter of inquiry asking for information on slx specific points was addressed to representative firms in the optical trade. The results of these inquiries has been such as to satisfy the guild that the supply of optical glass available for the manufacture of telescopes, binoculars, range-finders, and other service instruments is sufficient for the purpose. Under this head there seems to be no call for any special effort to improve upon existing conditions, though the supply of English glass has not always been adequate in quantity, and delays have been experienced in obtaining quick delivery.

The representative of Messrs. Chance Bros., who was a member of the Technical Committee referred to above, has assured the committee that since the outbreak of hostilities the firm has considerably increased (in fact, quadrupled) the capacity of its plant for the manufacture of optical glass, and is fully prepared to extend this plant still further.

\section{(b) Photography and Micrography.}

(2) With regard to the manufacture of photographic and microscopic lenses the case stands otherwise. The requirements of the manufacturing trade in these respects are not definitely standardised as in the case of the instruments already referred to. To facilitate new and important developments it is necessary that the lens manufacturer should have recourse to a greater variety of glasses than are, in fact, manufactured at the present time in this country. It is further necessary that larger stocks should be held than is the custom at the present time of the various glasses produced. The guild, therefore, is of opinion that serious inconvenience is certain to result to the manufacturing trade if the supply of German glass is cut off for any considerable length of time. The amount of glass demanded, especially for photographic purposes, is very considerable, and the guild is of opinion that the attention of the authorities might usefully be directed to this opportunity for a considerable development of British glass manufacture in this direction. One difficulty the guild understands to be the defective supply of pure barium compounds.

\section{(c) Variety of Glass Obtainable Inadequate.}

(3) From a wider point of view and more generally, the variety of English glasses offered is not sufficient for all the requirements of optical instrument-makers, especially for the more recently developed and important optical designs. Thus, whilst the leading English firm listed only twenty to thirty types of glass, the leading German firm listed about seventy types, every one stocked. Barium glass of high refraction and low dispersion, i.e. having a high value of the "anti-dispersion" coefficient, is reported as specially difficult to obtain in England.

\section{Research}

(4) The desirability of the provision of facilities for research upon the manufacture of optical glass has been carefully considered and has been found to be a difficult question. From the evidence submitted it appears that if one special object of research could be attained the result would be highly advantageous. This object is the discovery of a refractory lining of the melting "pot" which would resist the action, at

NO. 2369, VOL. 95] 
melting temperatures, of the materials used in the glass mixtures, and leave the contents of the pot uncontaminated at the conclusion of the operation. This research would probably be a long and costly one, and is such as might most appropriately be undertaken by the National Physical Laboratory, especially as certain details in the manufacture of optical glass may come under review during the inquiry.

\section{Authoritative Testing of Glass.}

(5) In another direction evidence was submitted to the guild to the effect that it would be distinctly advantageous to the optical trade if increased facilities for the authoritative determination of the optical constants and relative absorption of samples of glass submitted for test could be provided at the National Physical Laboratory

\author{
THE FUTURE.
}

Facilities for Education a Matter of Great Urgency.

(6) In still another direction evidence, additional to evidence collected before the outbreak of hostilities, was elicited that the facilities for education in technical optics are very inadequate. It was shown that not only could some of the present difficulties connected with the supply of optical glass probably be diminished, but that the output of optical instruments for national purposes would be increased, and that the optical trade would be substantially benefited in other directions if such facilities were largely extended. The Technical Optics Committee of the guild was originally appointed, early in the year 19I4, for the purpose of "inquiring into the need of an Institute of Technical Optics and the steps to be taken in connection therewith, and in due course it submitted a "statement" on the subject, which was published in the annual report of the guild, I9I4, pp. $3^{I-34}$. The committee had further reported to the Executive Committee of the guild at its July meeting, and the report was adopted with a few alterations, and is printed at the end of this report.

(7) When the Technical Optics Committee met after the vacation, the other matters, apparently of more immediate urgency, referred to in this report, had arisen and took precedence of the earlier matter. In investigating these new questions it has become strongly evident that the earlier matter is of supreme and pressing importance.

The guild therefore recommends :-

(A) That better provision should be made at the National Physical Laboratory for the testing of samples of glass as to their physical and optical properties, and that the director of the National Physical Laboratory be approached on the subject.

(B) That facilities should be provided as speedily as possible for the carrying out, at the National Physical Laboratory, or elsewhere, of the researches connected with the manufacture of optical glass referred to in this report.

(C) That steps should be taken as speedily as possible to give effect to the recommendations of the previous report of the Technical Optics Committee of the guild in the direction of providing facilities for systematic, scientific, and manual training in technical optics, and the guild, recognising that educational training requires time, is strongly of opinion that this question is urgent and that the organisation of optical training should be taken in hand at once.

PREVIOUS REPORT REFERRED TO IN PARAGRAPH C, DATED JULY I4, I9I4.

Proposed Establishment of an Institute for Technical Optics.

The British Science Guild has had under consideration for some time the inadequate provision for, and NO. 2369 , VOL. 95] the unsatisfactory state or, the technical training in optics in the British Isles. The subject was brought to its notice by Sir Thomas Barlow, formerly president of the Royal College of Physicians, in a communication to the president of the guild, and was considered to be of such importance by the Executive Committee that a Special Committee was formed to deal with it. The Special Committee has now reported.

The establishment of such an institute has been under discussion for some years, and there is a remarkable consensus of expert opinion, both as to the necessity and the urgency for action, from many and diverse points of view, scientific, industrial, and national.

The London County Council, which has gone into the matter very thoroughly, has not felt itself in a position to provide from the funds under its control the initial capital expenditure of some $40,000 l$. for the erection and equipment of the proposed institute, although a site was actually purchased for the very purpose by the governing body of the Northampton Polytechnic Institute so far back as I908. The Finance Committee of the council is understood to be of opinion that the project is so essentially of national importance that it would be unfair to saddle London ratepayers with the whole cost. It is, however, believed that if the question of capital expenditure can be solved, the maintenance of the institute could be assured by grants from the Board of Education and from the London. County Council, and by students' fees. As an additional reason for expedition, it may be pointed out that the governing body of the Northampton Polytechnic Institute may not be in a position to carry much longer the heavy burden of the mortgage interest on the purchase money above referred to, and the amortisation of the capital amount.

GEOLOGY IN RELATION TO THE EXACT SCIENCES, WITH AN EXCURSUS ON GEOLOGICAL TIME. ${ }^{1}$

$\mathrm{T}$ is often said that figures can be made to prove anything; and certain it is that a series of arithmetical operations does sometimes serve as introduction to very strange conclusions. The fault, of course, is not in the tool, but in the hand that uses it. In the larger issues of geology especially, where the gulf to be bridged between data and conclusions is so often a wide one, ingenuity of reasoning ought surely to be accompanied by a due sense of responsibility in the handling of figures. Calculation, in such applications, is by no means so simple an art as it may appear. In wrestling with problems of the kind indicated, and, I must add, in reading some very fascinating speculations by geologists of high standing, I have often wished that some obliging mathematician would put forth a small manual of applied arithmetic for the guidance of workers in the descriptive sciences. There are absolutely necessary precautions to be observed when calculation is based upon data always partial and at best roughly approximate, and these precautions are too often neglected. To be safe, we must have some conception of the probable error attaching to our observations, and we must note how the initial errors may be multiplied in the process of calculation. Especially there is the cumulation of error which must ensue when results obtained in this fashion are used as links in a chain of deduction. Here it is quite inadequate to say that the chain is no stronger than its weakest link; it is of necessity far weaker than its weakest link.

1 From a Presidential Address delivered before the Yorkshire Geological Society by Alfred Harker, F. R.S. Reprinted from the Proceedings of the
Society. 